\title{
Discussion on Importance and Entry Point of Imitation Writing in Composition Instruction
}

\author{
Jincheng Huang \\ Department of Music and Dance \\ Academy of Arts and Films \\ Chengdu University \\ Chengdu, China 610106
}

\author{
Shuhong Li \\ Department of Music and Dance \\ Academy of Arts and Films \\ Chengdu University \\ Chengdu, China 610106
}

\begin{abstract}
Imitation writing is an important means in composition instruction. One can faster get unique writing techniques of classical works of master through imitation writing. But because some teachers and young students do not fully realize its importance and all kinds of new technology and new trend of thought have impacted since the 20th century, the importance of this teaching method is suffering from impact in the class of composition instruction. Paying attention to the importance of imitation composition and starting with study and research on classical music score and classical works on theory of composition can help young students to grow rapidly and it is the only way for them to form unique personality in composition.
\end{abstract}

Keywords-imitation writing; composition instruction; importance; entry point

\section{INTRODUCTION}

Imitation writing on classical works of classicism once was important teaching method in composition instruction of Chinese universities. But with the development of the times and impact of various new technology and new trend of thought, the teaching method that old generation of composers in China pay attention to for a long time is suffering from serious challenges. It is very difficult for young students to settle to carry out training of imitation writing on works of masters. They hope to establish unique personality in composition of their own as soon as possible.

\section{DISCUSSION ON IMPORTANCE OF IMITATION WRITING}

Composition is a systematic project, very elaborate and complicated. Classical works that can leave a good name forever can bear closer analysis on many aspects. It is important means and shortcut to get precious composition techniques of masters through deeply analyzing these classical works and conducting imitation writing. However, young students are not aware of the importance of imitation writing in the process of learning composition. There are many reasons that lead to this result. For example, some teachers do not pay adequate attention to the role played by imitation writing in composition instruction. And some students lack deep understanding for composition.

Imitation is a precious wealth endowed by the nature for

This paper is the 2016 "Social Sciences Research Fund Project for Youth by the Ministry of Education", and the stage achievements of the 2015 " Scientific Research Startup Project of Chengdu University for Introducing Talents" (2081916003) living creatures on the earth. Animals learn to walk, fly, swim, hunt, nest and escape through imitation. Human learn to speak and labor through imitation and then create splendid human civilization. This kind of great ability is despised or neglected by a small number of music students and teachers. They think that it is vulgar to imitate. They will be despised by others if they use triad. Teachers will criticize them if they use functional classical harmony such as I-S-II6-K46-D-I. It is necessary to correctly guide this kind of superficial ideas of students and emphasize importance of imitation writing in forming high quality personality in composition in the future.

Nothing can be created without foundation. Composition is a systematic and complicated project. Rhythmic pattern can be written into a doctoral thesis by using treatise ${ }^{1}$, let alone mutual alternations and changes of musical interval, melody, chord and texture. Present outstanding predecessors of composition in China emphasized the importance of imitation writing in composition instruction long ago. For example, Mr. Luo Zhongrong of more than 90 years old, the leading authority of Chinese composer, professor of composition department of Chinese Conservatory of Music, says, “... it is very difficult and even impossible for students to come up with many different music texture patterns in short period. So they shall learn from masters modestly! In learning, imitation is not drawback but absolutely necessary. From ancient to modern times, does not any master start from imitating predecessors?"2 The ability to imitate composition techniques of predecessors can be acquired through analyzing music literatures. "Analysis on music literature is the most important part of the book of Preliminary Practice of Composition and it runs through the whole book from beginning to end. Besides, any problem discussed in this book starts from analysis on works",; another master composer, the excellent music educator, professor Du Mingxin ${ }^{4}$ of nearly 90 years old in composition department of

\footnotetext{
${ }^{1}$ Zhang Wei. morphology and function of the structure of the music rhythm: Rhythm Structure Force and Dynamic [M]. Shanghai: Shanghai Conservatory of Music Press .2009

2 Luo Zhongrong. Preliminary Exercise of Composition[M]. Beijing: China Renmin University Press .2003 Foreword P4

3 Luo Zhongrong. Preliminary Exercise of Composition[M]. Beijing: China Renmin University Press .2003 Foreword P4.

${ }^{4}$ Du Mingxin (1928 ), famous Chinese composer, professor and $\mathrm{Ph}$.D. adviser of the Central Conservatory of Music. His students include former Zhao Jiping, former Chairman of the Chinese Musicians Association
} 
Central Conservatory of Music who has cultivated a large number of outstanding composers including the present chairman of Chinese Musicians Association, also puts forward, "in learning composition techniques, it is necessary to be good at learning and researching various excellent works at all times and in all over the world and research their structure, technique and characteristics"

\section{ENTRY POINT OF IMITATION WRITING}

In composition instruction, except for guiding students to strengthen the understanding of importance of imitation writing, teachers shall also teach students to use correct entry point to carry out practice of imitation writing.

Since Mr. Xiao Youmei, the pioneer of Chinese professional music education, created the first professional music college-Shanghai National Academy of Music in 1920s and 1930s, China has always followed teaching system of composition in the west. After nearly a century of development, China has made great progress on composition instruction and gradually formed unique composition instruction system in universities. The biggest characteristic is that China splits composition course into four items of composition: musical form, harmony, polyphony and orchestration. Although more and more domestic insiders doubt whether it is reasonable to divide composition instruction into four items, it is undeniable that since the reform and opening up, China has achieved amazing achievements on teaching system of four items. Taking academic achievements of musical form analysis on western classical music as an example, the masterwork Analysis and Creation on Music of Yang Ruhuai ${ }^{6}$, the leading authority of music analysis field in China not only makes elaborate research on musical form structure of western traditional music, but also creatively puts forward such research results full of academic value as five principles of musical form structure, differences between statement structure and musical form structure and qualitative changes arising from quantitative changes in musical form structure; taking academic achievements of research on orchestration as an example, Mr. Yang Liqing ${ }^{7}$, the former dean of Shanghai Conservatory of Music and Chinese famous composer, devotes his lifetime to completing Orchestral Instruments Course (three volumes), which includes 1,592 pages, with sample scores of 1,198 . It makes incisive analysis on techniques of orchestration of famous composers in Chinese and western music history. In

and Ye Xiaogang, current Chairman of the Chinese Musicians Association, as well as a large number of famous composers such as Xu Peidong, Wang Liping, Jin Ping etc.

${ }^{5}$ Cao Guangping. Tutorial of Small Works Composition [M]. Guangzhou: New Century Press (2008). Du Mingxin made a preface for the works.

${ }^{6}$ Yang Huairu (Aug. 1925-May 2012), Professor and Ph.D.adviser of China Central Conservatory of Music, dean of Chinese Music Analysis Community, his students include dean, Professor Gao Jiajia of Department of composition of China Conservatory of Music, vice president, Professor Cai Qiaozhong of Xinghai Conservatory of Music Dean, vice president, professor WU Chunfu of School of Music of Hunan Normal University.

${ }^{7}$ Yang Liqing (1942 to 06-10-2013), China famous composer, music theorist, professor of Shanghai Conservatory of Music, former dean of Shanghai Conservatory of Music. "Orchestration tutorial" is his most influential works in his lifetime. addition, there are also a large number of works such as general higher education "Nine Five" national key teaching materials-book series of China art education large system introduced by Shanghai Music Publishing House, book series of general higher education "11th Five-year" national planning teaching materials introduced by Higher Education Press, and book series of Music Self-study Series- Composition Volume. So to speak, these works tease Chinese and western composition techniques from different perspectives and can completely represent the highest level of research on four items of composition in China. Guiding students to read up these works in detail and start with imitation writing of sample scores analyzed in these works can make students clearly know the target and avoid detours, let imitation writing training become more systematic and scientific. It is no doubt the best way to engage in composition instruction.

At the meantime, paying attention to imitation of predecessors in teaching does not mean denying innovation of students nor neglecting new music style, but adopting correct ways to teach. In teaching method aiming at training innovation of students, one way is that when students have certain traditional skill, they begin to explore new skills and new styles, and then gradually establish unique personality in composition; another way is that students conduct proper innovation consciously under the leadership of teachers. When discussing related problems and thoughts on Composition Method of Coase and composition instruction, Peng Zhimin, dean of Wuhan Conservatory of Music puts forward, "...The so-called new music style is brought into teaching process by Coase "from the beginning". ... It may let learners stand on standpoint of "today" from the initial stage and equally contact and learn "previous" or "existing" things... will not artificially or forcibly separate music before and after the 20th century as well as not regard new music composition as "unnecessary". But the premise to implement this way is good guidance of experienced teachers. Otherwise, the exploration on this kind of new music and new skills is likely to become formalistic. In training process of imitation writing, no matter the mock object is traditional works in western classical period or western avant-garde techniques rich in pioneering spirit in 20th century, carefully reading up masters' works and reviewing psychological journey of masters in creation process can promote young students to grow rapidly and form high quality personality in composition early.

\section{CONCLUSION}

Imitation is not equal to philistinism. All innovations must base on researches of predecessors. The existing Chinese and western classical music works and theoretical achievements obtained through analyzing these works are inexhaustible sources to guarantee quality of music creation and contain precious spiritual wealth of human. It is effective shortcut to get precious creation techniques of masters and the only way for young students to form unique personality in composition in the future through guiding young students to carefully analyze classical masterwork of masters and carry out

\footnotetext{
${ }^{8}$ Peng Zhimin. focus on pre-conceived expansion styles range-Problems and Thought on Kos "Composition Method" and Its Composition Teaching. Central Conservatory of Music [J]. 4th edition, P17, 2002.
} 
imitation writing. Under the present composition instruction, the teaching method of imitation writing still has vigorous life and shall receive further attention.

\section{REFERENCES}

[1] Paul Hindemith: The Craft of Musical Composition: Book 1$3[\mathrm{M}]$.Schott; 4 th ed.edition, 1984.10.

[2] Arnold Schoenberg: Fundamentals of Musical Composition [M].Faber \& Faber; New Ed edition, 1999.

[3] Samuel Adler:The Study of Orchestration[M].W.W.Norton \& Company;3rd edition,2002.4.

[4] Ron Gorow: Hearing and Writing Music: Professional Training for Today`s Musician [M].September Publishing; 2nd ed edition,2015.2.

[5] Yang Ruhuai. Analysis and Creation of Music (revised edition) [M], Beijing: People's Music Publishing House, 2003.

[6] Luo Zhongrong. Luo Zhongrong. Preliminary Practice of Composition [M], Beijing: China Renmin University Press, 2003.

[7] Zhao Xiaosheng. Traditional Composition Techniques [M], Shanghai: Shanghai Educational Publishing House, 2003.

[8] Yao Henglu. Basic Training of Composition [M], Beijing: People's Music Publishing House, 2011.

[9] Yao Henglu. Comprehensive Analysis Course on Music TechniquesIntegrated Curriculum of Composing Technique Theories [M], Beijing: Higher Education Press, 2009.

[10] Yang Qing. Basic Course of Composition [M], Beijing: Higher Education Press, 1991. 